\title{
PIK3CA Mutational Status Is Associated with High Glycolytic Activity in ER+/HER2- Early Invasive Breast Cancer: a Molecular Imaging Study Using $\left[{ }^{18} \mathrm{~F}\right]$ FDG PET/CT
}

\author{
Heinrich Magometschnigg, ${ }^{1}$ Katja Pinker, ${ }^{2}$ Thomas Helbich, ${ }^{1}$ Anita Brandstetter, ${ }^{3}$ \\ Margaretha Rudas, ${ }^{4}$ Thomas Nakuz, ${ }^{5}$ Pascal Baltzer, ${ }^{1}$ Wolfgang Wadsak, ${ }^{5}$ \\ Marcus Hacker, ${ }^{5}$ Michael Weber, ${ }^{1}$ Peter Dubsky, ${ }^{6,7}$ Martin Filipits ${ }^{3}$ \\ ${ }^{1}$ Department of Biomedical Imaging and Image-guided Therapy, Molecular and Gender Imaging, Medical University of Vienna, Vienna, \\ Austria \\ ${ }^{2}$ Department of Radiology, Breast Imaging Service, Memorial Sloan Kettering Cancer Center, New York, USA \\ ${ }^{3}$ Institute of Cancer Research, Department of Medicine I, Comprehensive Cancer Center, Medical University of Vienna, Vienna, Austria \\ ${ }^{4}$ Department of Pathology, Medical University of Vienna, Vienna, Austria \\ ${ }^{5}$ Department of Biomedical Imaging and Image-guided Therapy, Division of Nuclear Medicine, Medical University of Vienna, Vienna, \\ Austria \\ ${ }^{6}$ Department of Surgery, Comprehensive Cancer Center, Medical University of Vienna, Vienna, Austria \\ ${ }^{7}$ Department of Surgery, Breast Centre Clinic St. Anna, Lucerne, Switzerland
}

\begin{abstract}
Purpose: In PIK3CA mutant breast cancer, downstream hyperactivation of the PI3K/AKT/mTOR pathway may be associated with increased glycolysis of cancer cells. The purpose of this study was to investigate the functional association of PIK3CA mutational status and tumor glycolysis in invasive ER+/HER2- early breast cancer.

Procedures: This institutional review board-approved retrospective study included a dataset of $67 \mathrm{ER}+/ \mathrm{HER} 2-$ early breast cancer patients. All patients underwent 2-deoxy-2-[ $\left.{ }^{18} \mathrm{~F}\right] \mathrm{fluoro}-\mathrm{D}$ glucose positron emission tomography/X-ray computed tomography $\left(\left[{ }^{18} \mathrm{~F}\right] \mathrm{FDG} \mathrm{PET} / \mathrm{CT}\right)$ and clinico-pathologic assessments as part of a prospective study. For this retrospective analysis, pyrosequencing was used to detect PIK3CA mutations of exons 4, 7, 9, and 20. Tumor glucose metabolism was assessed semi-quantitatively with $\left[{ }^{18} \mathrm{~F}\right] \mathrm{FDG} \mathrm{PET} / \mathrm{CT}$ using maximum standardized uptake values $\left(S U V_{\max }\right)$. SUV $V_{\max }$ values were corrected for the partial volume effect, and metabolic tumor volume was calculated using the volume of interest automated lesion growing function 2D tumor size, i.e., maximum tumor diameter was assessed on concurrent pretreatment contrast-enhanced magnetic resonance imaging.

Results: PIK3CA mutations were present in $45 \%$ of all tumors. Mutations were associated with a small tumor diameter $(p<0.01)$ and with low nuclear grade $(p=0.04)$. Glycolytic activity was positively associated with nuclear grade $(p=0.01)$, proliferation $(p=0.002)$, regional lymph node metastasis $(p=0.015)$, and metabolic tumor volume $(p=0.001)$ but not with tumor size/T-stage.
\end{abstract}

Heinrich Magometschnigg and Katja Pinker as well as Peter Dubsky and Martin Filipits contributed equally to this work.

Correspondence to: Peter Dubsky; e-mail: peter.dubsky@meduniwien.ac.at 
In invasive ductal carcinomas, median SUV max $_{\text {mas }}$ increased in PIK3CA-mutated compared to wild-type tumors; however, this increase did not reach statistical significance $(p=0.05)$. Multivariate analysis of invasive ductal carcinomas revealed $\left[{ }^{18} \mathrm{~F}\right] \mathrm{FDG}$ uptake to be independently associated with PIK3CA status $(p=0.002)$ and nuclear tumor grade $(p=0.046)$. Size, volume, and regional nodal status had no influence on glycolytic activity. PIK3CA mutational status did not influence glycolytic metabolism in lobular carcinomas. Glycolytic activity and PIK3CA mutational status had no significant influence on recurrence-free survival or disease-specific survival.

Conclusions: In ER+/HER2- invasive ductal carcinomas of the breast, glucose uptake is independently associated with PIK3CA mutations. Initial data suggest that $\left[{ }^{18} \mathrm{~F}\right] \mathrm{FDG}$ uptake reflects complex genomic alterations and may have the potential to be used as candidate biomarker for monitoring therapeutic response and resistance mechanisms in emerging therapies that target the PI3K/AKT/mTOR pathway.

Key words: PIK3CA mutations, PI3K/AKT/mTOR pathway, ER+/Her2- breast cancer, Glycolytic activity, $\left[{ }^{18}\right.$ F]FDG PET/CT, Biomarker imaging

\section{Introduction}

The PI3K/AKT/mTOR pathway plays a crucial role in multiple cellular processes that promote the proliferation, growth, and survival of cancer cells [1]. Mutations to the PIK3CA gene which encodes for the $\mathrm{p} 110 \alpha$ catalytic subunit of PI3K have been particularly implicated in breast cancer [2-4]. In ER+/HER2- breast cancer, the $\mathrm{PI} 3 \mathrm{~K} / \mathrm{AKT} / \mathrm{mTOR}$ pathway is frequently altered and PIK3CA mutations occur in almost half of these patients [2-4]. The frequency of alterations in this pathway suggests a crucial role for PI $3 \mathrm{~K}$ signaling in sustaining $\mathrm{ER}+$ breast cancer $[5,6]$. In addition, these alterations have been implicated in both de novo and acquired resistance to endocrine therapy $[3,7,8]$ and are associated with survival outcomes [2, 4].

Recent data suggest that the majority of mutated tumors may be associated with other oncogenic driver alterations that in turn might influence glycolytic activity $[9,10]$. Most recent work in mouse models highlights that PIK3CA controls all responses to insulin and in the context of breast cancer metabolic behavior, it is noteworthy that the same PIK3CA mutations which lead to hyperactivation of the $\mathrm{PI} 3 \mathrm{~K} / \mathrm{Akt} / \mathrm{mTOR}$ pathway can also be associated with increased glycolysis in cancer cells [11-14].

Molecular imaging with positron emission tomography/Xray computed tomography using the radiotracer 2-deoxy-2$\left[{ }^{18} \mathrm{~F}\right]$ fluoro-D-glucose $\left(\left[{ }^{18} \mathrm{~F}\right] \mathrm{FDG}\right.$ PET/CT) allows the noninvasive detection, quantification, and visualization of tumor glycolysis $[15,16]$. Due to this advantage, $\left[{ }^{18} \mathrm{~F}\right] \mathrm{FDG}$ PET/CT has been established as a valuable tool for staging, neo-/ adjuvant and palliative therapy monitoring, and follow-up of breast cancer patients [15, 17-31].

We hypothesized that PIK3CA mutation will be associated with increased glycolysis of cancer cells. Therefore, the aim of this study was to investigate the functional associations of PIK3CA mutational status, clinico-pathologic factors, and glycolytic activity in ER+/HER2- early breast cancer.

\section{Materials and Methods}

\section{Patient Population}

From September 2009 to September 2014, 233 patients were enrolled in a prospective institutional review board (IRB)-approved single-institutional study that investigated combined $\left[{ }^{18} \mathrm{~F}\right] \mathrm{FDG}$ PET/CT and magnetic resonance imaging (MRI) of the breast. The inclusion criteria for this study were as follows: age $\geq 18$ years; suspicious finding on mammography or breast ultrasound (BIRADS ${ }^{\circledR}$ categories 4 and 5 ); not pregnant or breastfeeding; no prior intervention (e.g., breast biopsy, neoadjuvant chemotherapy); and histopathological verification of the imaging finding. All patients signed a written, informed consent before undergoing a dedicated prone breast $\left[{ }^{18} \mathrm{~F}\right] \mathrm{FDG} \mathrm{PET} / \mathrm{CT}$. In this study, we performed an IRB-approved retrospective analysis of $\left[{ }^{18}\right.$ F]FDG PET/CT of patients with ER+/HER2- breast cancer. For all patients' demographic data, menopausal status histologic type; tumor grade; receptor status; tumor proliferation rate (ki67), nodal status, date of progression (local recurrence, distant metastases) to determine duration (months) of recurrence-free survival (RFS); and date and cause of death or date of last follow-up to determine duration (months) of disease-specific survival (DSS) were recorded.

Of the 207 patients who underwent a dedicated prone breast $\left[{ }^{18} \mathrm{~F}\right] \mathrm{FDG}$ PET/CT, 113 were diagnosed with ER+/ HER2 - breast cancer. Two patients were excluded due to diagnosis of primary metastatic disease. Forty-one had to be excluded due to insufficient or unavailability of tissue for mutational analysis. Three patients with small tumors $(<10-$ mm-long axis diameter) were excluded due to possible partial volume effects. Thus, 67 ER+/HER2- early breast cancer patients were eligible for our retrospective analysis study. The consort flow diagram displays the progress of all participants through the study (Fig. 1). 


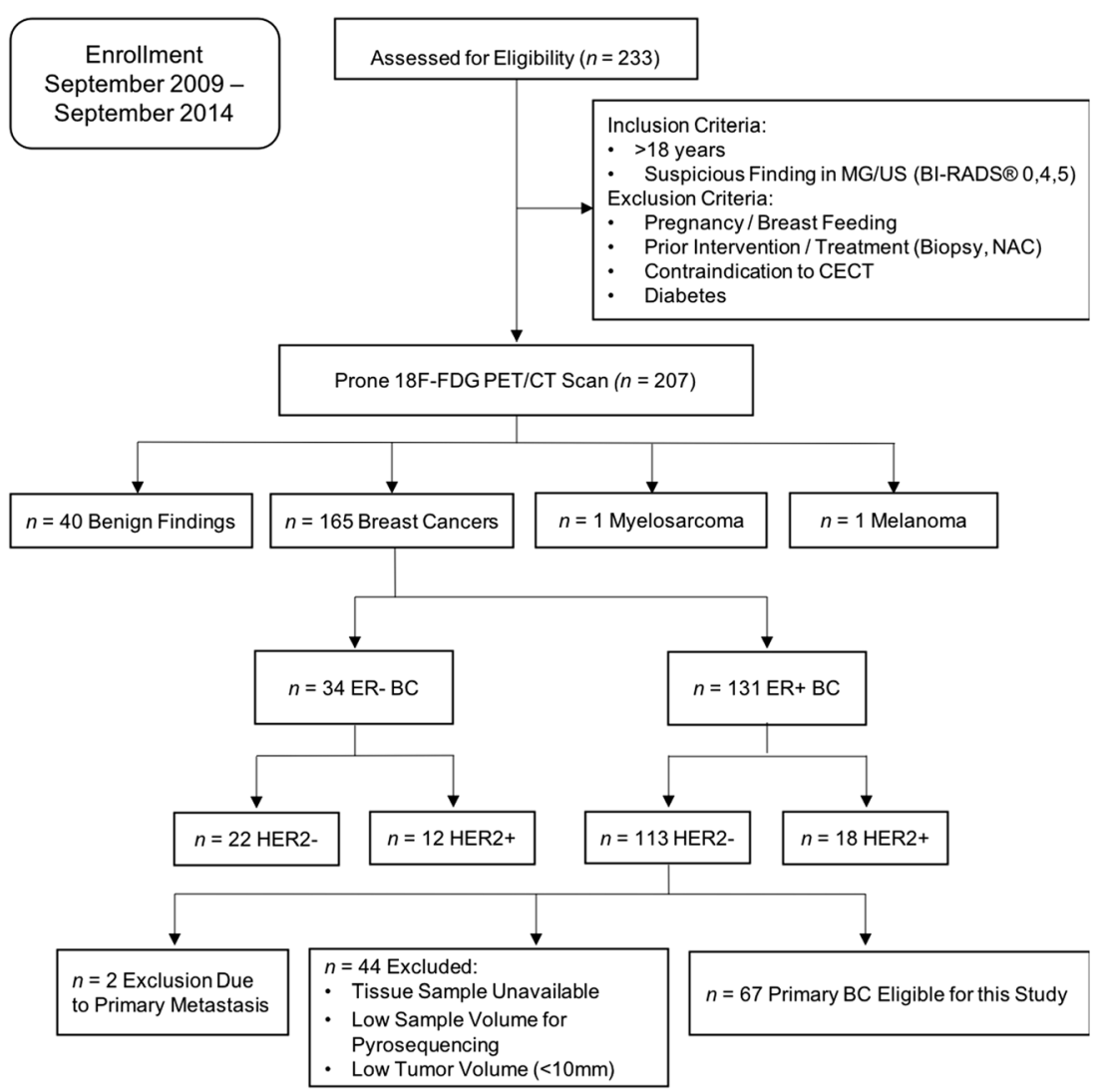

Fig. 1. Consort diagram.

\section{$\left.{ }^{18} \mathrm{~F}\right] F D G$ PET/CT Imaging}

$\left[{ }^{18} \mathrm{~F}\right] \mathrm{FDG}$ was prepared in-house using a fully automated radiosynthesizer (GE FASTlab ${ }^{\circledR}$, GE Healthcare, USA) with dedicated software and single-use cassettes [32, 33].

Prone $\left[{ }^{18} \mathrm{~F}\right] \mathrm{FDG}$ PET/CT of the breast was performed using a combined whole-body PET/CT in-line system (Biograph 64

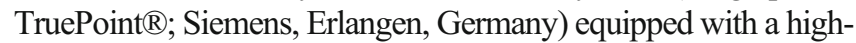
resolution PET scanner and a 64-row detector $\mathrm{CT}$ scanner. Prior to injection of the radiotracer, patients fasted for at least $5 \mathrm{~h}$. If plasma glucose was less than $150 \mathrm{mg} / \mathrm{dl}(8.3 \mathrm{mmol} / \mathrm{l})$, each patient was injected intravenously with $200-350 \mathrm{MBq}\left[{ }^{18} \mathrm{~F}\right] \mathrm{FDG}$ based on body weight. After $\left[{ }^{18} \mathrm{~F}\right] \mathrm{FDG}$ injection, patients rested for a 60 min uptake period. This was followed by image acquisition where initially, a prone low-dose CT scan without contrast agent from the base of the skull to the upper abdominal region was acquired for attenuation correction and subsequently, a highresolution, prone PET dataset was recorded over the same region. Raw data were reconstructed using an ordered subset expectation maximization (OSEM) algorithm with point spread function correction (PSF) correction ("TrueX") [34-36]. Four iterations with 21 subsets were used, with a matrix size of $168 \times 168$ (pixel size $4.1 \times 4.1 \mathrm{~mm}$ ) and a slice thickness of $5 \mathrm{~mm}$. No postreconstruction filter was applied (“ALLPASS" option). $\left[^{18}\right.$ F]FDG PET/CT Analysis

All $\left[{ }^{18} \mathrm{~F}\right]$ FDG PET/CT images were assessed in consensus by a radiologist and a nuclear medicine physician with both $>10$ years of experience. In all images, $\left[{ }^{18} \mathrm{~F}\right] \mathrm{FDG}$ uptake as a measure of glycolytic activity was quantified using maximum standardized uptake value $\left(\mathrm{SUV}_{\max }\right)$ [37]. To determine $\mathrm{SUV}_{\max }$, a three-dimensional volume of interest (VOI) was placed around the primary breast tumor using HERMES Hybrid 3D Viewer (version 2.0, Hermes Medical Solutions). The VOI was established using the Region Grow function with a fixed threshold as determined by the reader to represent PET metabolic tumor volume but excluding physiologic $\left[{ }^{18} \mathrm{~F}\right] \mathrm{FDG}$ uptake in surrounding tissues. Lymph nodes were not assessed. Whenever a fixed threshold was not applicable, the VOI was edited slice-by-slice according to CT lesion borders, which were assessed in side-by-side comparison with concurrent contrast-enhanced magnetic resonance images of the tumors. For all lesions size (largest diameter) either the right-left, cranio-caudal, and anteriorposterior directions were recorded for determination of $\mathrm{T}$ stage. To adjust for partial volume effect, the previously published partial volume correction method by Knausl et al. was applied [35]. 
a

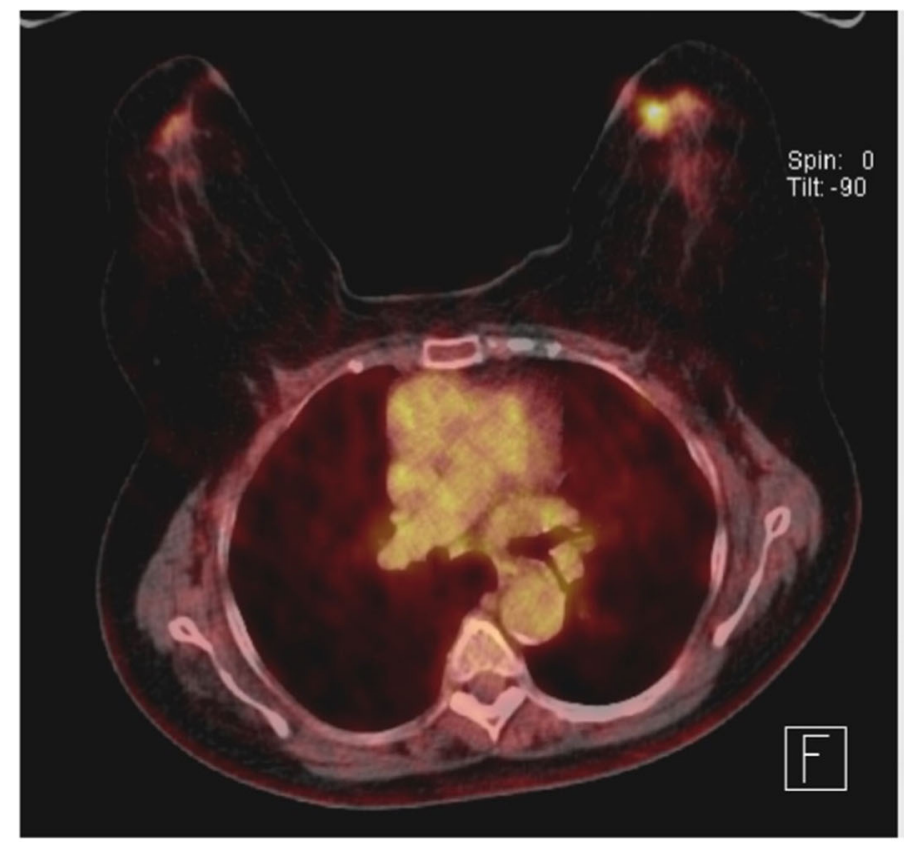

\section{b}

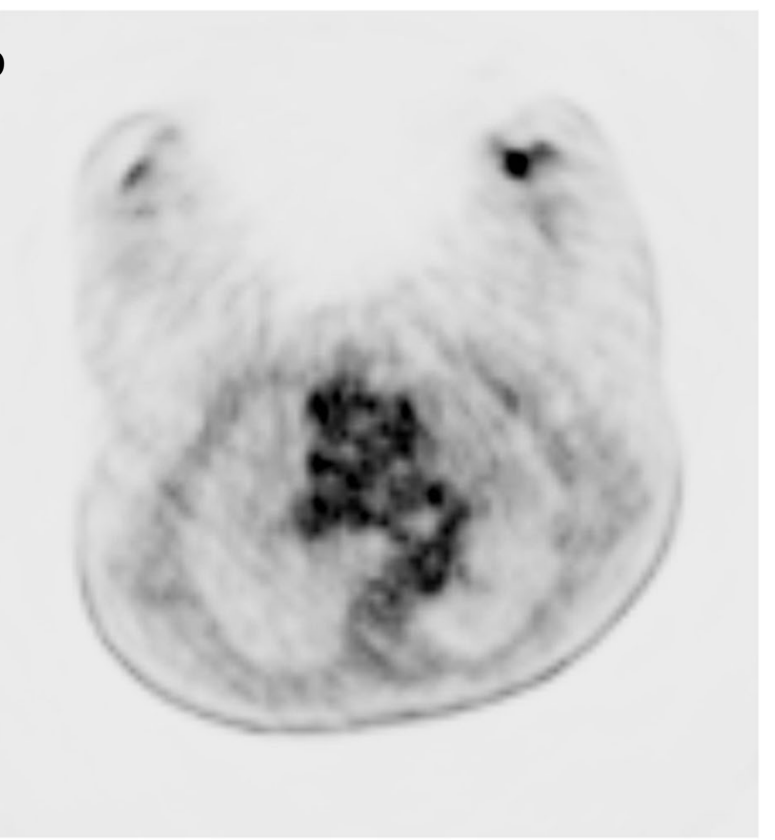

C

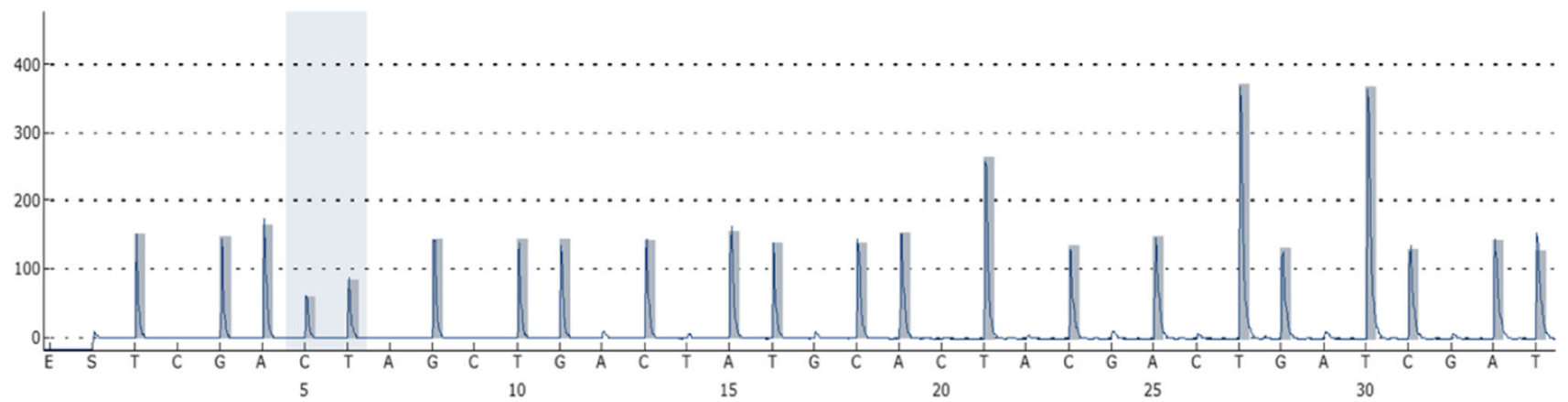

Fig. 2. Seventy-eight-year-old patient with a $30-\mathrm{mm}$ mass lesion in her left breast (9 o'clock position). a Axial hybrid $\left[{ }^{18} \mathrm{~F}\right] \mathrm{FDG}$ $\mathrm{PET} / \mathrm{CT}$ image with a high focal $\left[{ }^{18} \mathrm{~F}\right] \mathrm{FDG}$ uptake in a mass lesion in the left breast. $\mathbf{b}$ Corresponding, unfused, attenuationcorrected axial $\left[{ }^{18} \mathrm{~F}\right] \mathrm{FDG}$ PET image $\left(\mathrm{SUV}_{\max }\right.$ was 6.5$)$. Histopathology: IDC grade II. c Pyrosequencing revealed a PIK3CA mutation in exon 20 (41.45\% c.3140A>G, p.H1047R).

\section{Histopathology}

Diagnosis of breast cancer was established by one pathologist (M.R.) with more than 20 years of experience using specimens from image-guided needle biopsy, surgical biopsy, mastectomy, or lumpectomy.

\section{Mutational Analysis}

DNA extraction for mutational analysis was performed using the QIAamp DNA FFPE Tissue Kit (Qiagen, Hilden, Germany). Thereafter, pyrosequencing was used to detect PIK3CA mutations of exons 4, 7, 9, and 20 (Figs. 2 and 3). For pyrosequencing, the regions of interest were amplified via polymerase chain reaction (PCR) using the PyroMark PCR Kit (Qiagen, Hilden, Germany). We used the PCR primers for PIK3CA exons 20 and 9 as in Nosho et al. [38].
However, while the sequencing primers for PIK3CA exon 20 were based on the primers in Nosho et al., we slightly modified them for PIK3CA exon 9 (9RS-1 and 9RS-3) [38].

Pyrosequencing was performed on a PyroMark Q24 MDx Instrument according to the manufacturer's user manual (Qiagen, Hilden, Germany). To design the different pyrosequencing assays and to analyze the results, we used the PyroMark Q24 Application Software 2.0 (version 2.0.6) (Qiagen, Hilden, Germany).

\section{Survival Outcomes}

For the assessment of RFS and DSS, all patients underwent clinical and imaging follow-up with mammography, sonography, or computed tomography until progression, followed by routine follow-up until death. At the discretion of the treating physician, some patients were also followed with 

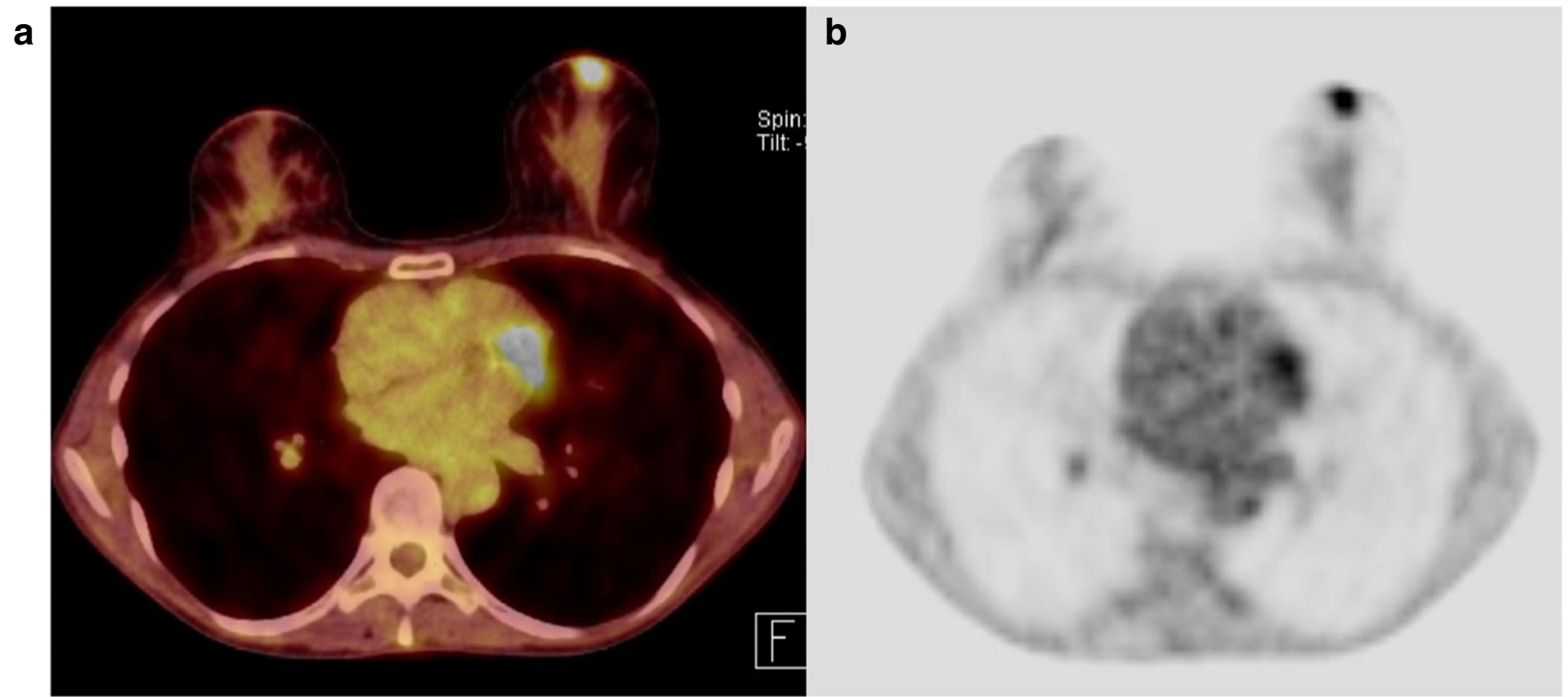

C

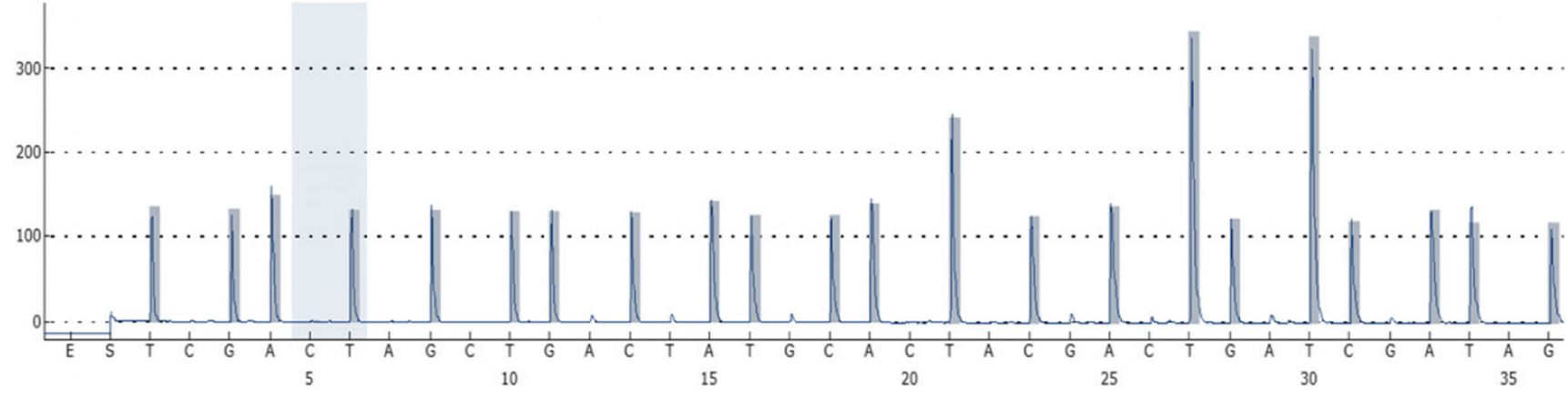

Fig. 3. Forty-seven-year-old patient with a 15-mm mass lesion in her left breast. a Axial hybrid $\left[{ }^{18} \mathrm{~F}\right] \mathrm{FDG} P E T / C T$ image with a focal $\left[^{18} \mathrm{~F}\right] F D G$ uptake in a retroareolar mass lesion in the left breast. b Corresponding, unfused, attenuation-corrected axial $\left[{ }^{18}\right.$ F]FDG PET image (SUV $\max$ was 4). Histopathology: IDC II. c Pyrosequencing found wild-type PIK3CA in exons 4, 7, 9, and 20 (exon 20, hotspot highlighted).

MRI of the breast and positron emission tomography/ computed tomography scans. All local and distant recurrences were histopathologically verified [39].

\section{Statistical Methods}

All statistical analyses were performed using IBM SPSS Statistics version 24.0 (SPSS Inc., Chicago, IL, USA). Metric SUV data were described using median values. Survival data for patients who were alive were censored at the last date of follow-up at our institution. An association between mutational status with RFS and DSS survival was assessed using Kaplan-Meier analysis. The log-rank (Mantel-Cox) test was used to evaluate the differences between Kaplan-Meier curves. Association of $\mathrm{SUV}_{\max }$ and survival data was performed by using the Cox regression function. Statistical analysis was performed using histogram analysis and the KolmogorovSmirnov test, chi-square test, Fisher's exact test,
Wilcoxon-Mann-Whitney $U$ test or Kruskal-Wallis oneway ANOVA. For multivariate analysis, we used the binary logistic regression analysis (enter method, $p$ values for entry and remove limits 0.05 and 0.1 ; an interaction term of both covariates was included in the model to account for covariate interdependency) and the linear regression model. Where appropriate, bootstrapping using bias-corrected and accelerated method with 1000 samples was applied for robust estimation of confidence intervals. A $p$ value equal to or below 0.05 was considered to indicate statistical significance. Reported $p$ values pertain to $\mathrm{SUV}_{\max }$ values.

\section{Results}

Demographic, histopathological, and immunohistochemical results for 67 patients who were included in our retrospective study are summarized in Table 1.

The median follow-up time for all patients was 64 months (range, $0-103$ months). Ten patients $(15.15 \%)$ progressed 
Table 1. Demographic, histopathologic, and immunohistochemical characteristics of the study cohort $(n=70)$. Median follow-up time for all patients was 66 months

\begin{tabular}{|c|c|c|c|c|}
\hline Characteristics & $\begin{array}{l}\text { Total } \\
n=67\end{array}$ & $\begin{array}{l}\text { PIK3CA wild-type } \\
n=37\end{array}$ & $\begin{array}{l}\text { PIK } 3 C A \text { mutation } \\
n=30\end{array}$ & $p$ value \\
\hline \multicolumn{5}{|l|}{ Age (years) } \\
\hline Median & 64 & 63 & 66 & 0.49 \\
\hline \multicolumn{5}{|c|}{ Tumor size (longest diameter in contrast-enhanced MRI) } \\
\hline Median $(\mathrm{mm})$ & $22(11-90)$ & $25(11-90)$ & $17.5(12-75)$ & \multirow[t]{4}{*}{$0.06<\mathbf{0 . 0 1}$} \\
\hline T1c (11-20 mm) & $30(44.8 \%)$ & $10(27 \%)$ & $19(63.3 \%)$ & \\
\hline $\mathrm{T} 2(21-50 \mathrm{~mm})$ & $31(46.3 \%)$ & $22(59.5)$ & $10(33.3 \%)$ & \\
\hline $\mathrm{T} 3(>50 \mathrm{~mm})$ & $6(9 \%)$ & $5(13.5 \%)$ & $1(3.3 \%)$ & \\
\hline \multicolumn{5}{|l|}{ Tumor grade* } \\
\hline Grade 1 & $9(13.4 \%)$ & $3(8.1 \%)$ & $6(20 \%)$ & \multirow[t]{4}{*}{$0.07(\mathbf{0 . 0 4 * *})$} \\
\hline Grade 2 & $30(44.8 \%)$ & $13(35.1 \%)$ & $17(56.7 \%)$ & \\
\hline Grade 3 & $24(35.8 \%)$ & $17(46 \%)$ & $7(23.3 \%)$ & \\
\hline Grade n/a & $4(6 \%)$ & $4(10.8 \%)$ & $0(0 \%)$ & \\
\hline \multicolumn{5}{|l|}{ Estrogen receptor } \\
\hline Low $(10-20 \%)$ & $1(1.5 \%)$ & $1(2.7 \%)$ & $0(0 \%)$ & \multirow[t]{3}{*}{1} \\
\hline Medium (30-70 \%) & $4(6 \%)$ & $2(5.4 \%)$ & $2(6.7 \%)$ & \\
\hline High $(80-100 \%)$ & $62(92.5 \%)$ & $34(91.9 \%)$ & $28(93.3 \%)$ & \\
\hline \multicolumn{5}{|l|}{ Progesterone receptor } \\
\hline Negative $(<10 \%)$ & $13(19.4 \%)$ & $8(21.6 \%)$ & $5(16.7 \%)$ & \multirow{4}{*}{0.89} \\
\hline Low $(10-20 \%)$ & $7(10.5 \%)$ & $4(10.8 \%)$ & $3(10 \%)$ & \\
\hline Medium (30-70 \%) & $21(31.3 \%)$ & $10(27 \%)$ & $11(36.7 \%)$ & \\
\hline High $(80-100 \%)$ & $26(38.8)$ & $15(40.5 \%)$ & $11(36.7 \%)$ & \\
\hline \multicolumn{5}{|l|}{ Ki67 (\%) } \\
\hline$<20 \%$ & $23(34.3 \%)$ & $11(29.7 \%)$ & $12(40 \%)$ & \multirow{3}{*}{0.6} \\
\hline$\geq 20 \%$ & $42(62.7 \%)$ & $24(64.9 \%)$ & $18(60 \%)$ & \\
\hline Not applicable & $2(3 \%)$ & $2(5.4 \%)$ & $0(0 \%)$ & \\
\hline \multicolumn{5}{|l|}{ Nodal status } \\
\hline Negative & $42(62.7 \%)$ & $20(54.1 \%)$ & $22(73.3 \%)$ & \multirow[t]{5}{*}{0.27} \\
\hline 1-3 positive nodes & $10(14.9 \%)$ & $4(10.8 \%)$ & $6(20 \%)$ & \\
\hline 4-10 positive nodes & $9(13.4 \%)$ & $8(21.6 \%)$ & $1(3.3 \%)$ & \\
\hline$>10$ positive nodes & $3(4.5 \%)$ & $3(8.1 \%)$ & $0(0 \%)$ & \\
\hline Not applicable & $3(4.5 \%)$ & $2(5.4 \%)$ & $1(3.3 \%)$ & \\
\hline \multicolumn{5}{|l|}{ Menopausal status } \\
\hline Premenopausal & $14(20.9 \%)$ & $10(27 \%)$ & $4(13.3 \%)$ & \multirow[t]{3}{*}{0.18} \\
\hline Postmenopausal & $52(77.6 \%)$ & $27(73 \%)$ & $25(83.3 \%)$ & \\
\hline Not applicable & $1(1.5 \%)$ & $0(0 \%)$ & $1(3.3 \%)$ & \\
\hline \multicolumn{5}{|l|}{ Median follow-up (months) } \\
\hline Recurrence-free survival & 62 & 63 & 62 & 0.5 \\
\hline Disease-specific survival & 64 & 68 & 62 & 0.22 \\
\hline
\end{tabular}

*Lobular carcinomas were only grade 2 tumors (mutations $n=5 / 11 ; 45 \%)$ and were included in this table (11/30 grade 2 tumors)

**Results if only invasive ductal cancers were considered

during the follow-up period after a median interval of 49 months (range, 18-91 months), and five patients $(7.58 \%)$ died of breast cancer during the follow-up period at a median interval of 55 months (range, 37-69 months). One patient was excluded from survival analysis due to diagnosis and subsequent death from metastatic pancreatic cancer and three patients due to the decision to receive treatment and follow-up elsewhere.

\section{Mutational Analysis}

A mutation in the PIK3CA gene was observed in 30 (45\%) patients, whereas wild-type PIK3CA was found in 37 patients $(55 \%)$. Nucleotide exchange was found in exon 20 in 15 patients and in exon 9 in 10 patients. In four patients, a mutation in exon 4 was identified. In one patient, a mutation in exon 7 was found. Exon mutations were mutually exclusive.

\section{PIK3CA Mutational Status, Clinico-Pathologic Factors, and Glycolytic Activity}

Association of PIK3CA Mutational Status and ClinicoPathologic Factors PIK3CA mutation was significantly associated with a small tumor diameter $(p<0.01)$, albeit having a weak negative correlation of $r=-0.25(p=0.045)$. In contrast, PIK3CA mutations was not associated with metabolic tumor volume $(r=-0.101, p=0.418)$. RFS and DSS were not significantly different between patients with a PIK3CA mutant vs. wild-type tumor $(\mathrm{p}=0.418$ and $p=$ 0.499 , respectively; Fig. 4).

When invasive ductal carcinomas were stratified by nuclear grade, a PIK3CA mutation was found in $67 \%$ of grade 1 tumors $(n=9), 89 \%$ of grade 2 tumors $(n=19)$, and $29 \%$ of grade 3 tumors $(n=24)(p=0.04)$. Invasive lobular carcinomas $(n=11)$ were exclusively grade 2 tumors with a mutation in $45.5 \%$ of tumors. PIK3CA mutation was not found in the four non-ductal/non-lobular carcinomas. 

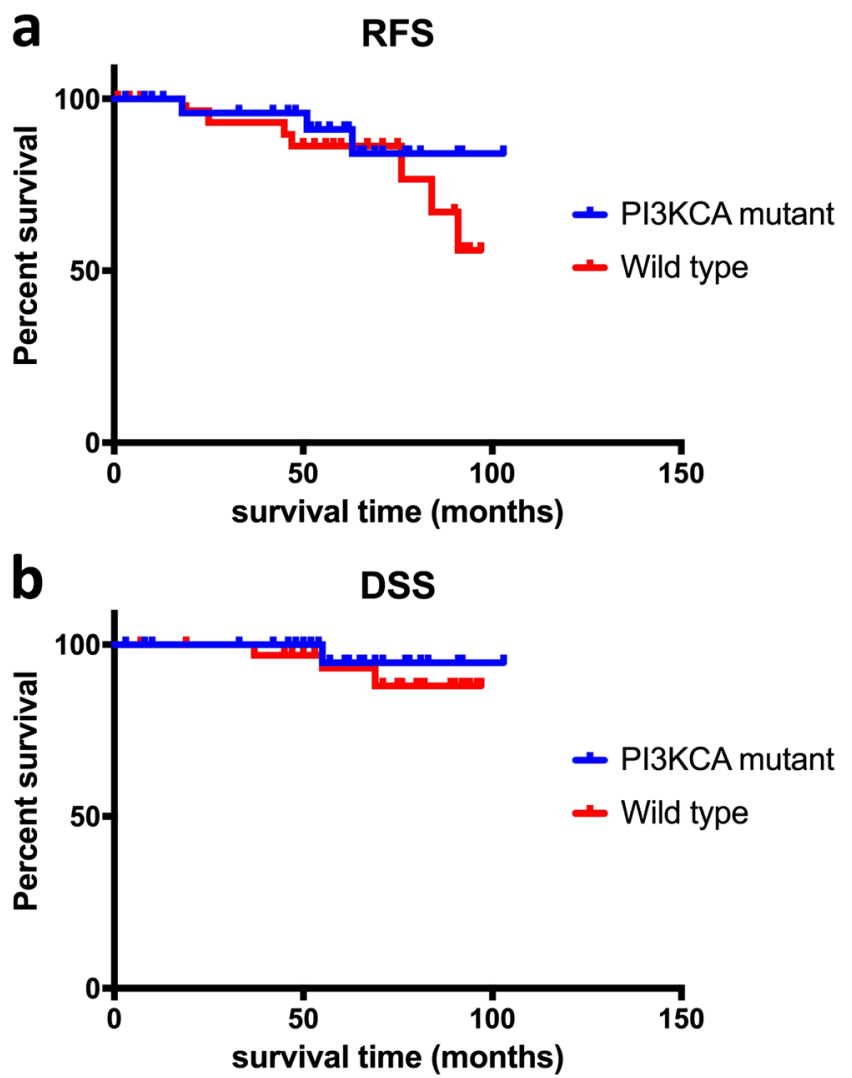

Fig. 4. a Recurrence-free survival (RFS) and b diseasespecific survival (DSS) by mutational status. Blue line, PIK3CA mutant; red line, wild-type. RFS and DSS were not significantly different between patients with a PIK3CA mutant vs. wild-type tumor ( $p=0.418$ and $p=0.499$, respectively).

In summary, PIK3CA mutations were associated with pathologic tumor features typically associated with good prognosis. However, this was not represented with a significantly increased survival.

Association of Glycolytic Activity and Clinico-Pathologic Factors All cancers showed focal $\left[{ }^{18} \mathrm{~F}\right] \mathrm{FDG}$ uptake which ranged from $\mathrm{SUV}_{\max }$ of 1.39 to 13.68 (SUV $_{\text {mean }}$ of 0.44 to 4.91; $\mathrm{SUV}_{\text {peak }}$ of 0.48 to 8.8$)$. $\left[{ }^{18} \mathrm{~F}\right] \mathrm{FDG}$ uptake showed a significant positive association with nuclear grade in invasive ductal carcinomas $(p=0.01)$ (Fig. 5a, Table 2). $\left[{ }^{18} \mathrm{~F}\right]$ FDG uptake also showed a significant positive association with high tumor proliferation defined as Ki-67 $\geq 20 \%$ $(p=0.002)$ (Fig. $5 b)$ and regional nodal metastasis $(p=$ 0.015; Fig. 5c) in all tumors. $\left[{ }^{18} \mathrm{~F}\right] \mathrm{FDG}$ uptake was not associated with the 2D tumors' largest diameter measured with contrast-enhanced MRI ( $p=0.12$; Fig. $5 \mathrm{~d})$. However, there was a significant positive association of glycolytic activity and metabolic tumor volume $(r=0.403 ; p=0.001)$. $\mathrm{SUV}_{\text {max }}$ was not associated with RFS $(\mathrm{B}=0.165 ; p=0.13)$ and DSS $(B=0.222 ; p=0.08)$.
In summary, high glycolytic activity was associated with tumor features that, in turn, are associated with a higher risk of recurrence.

Association of PIK3CA Mutational Status and Glycolytic Activity Patients who harbored a PIK3CA mutation had a higher median $\left[{ }^{18} \mathrm{~F}\right] \mathrm{FDG}$ uptake (median $\mathrm{SUV}_{\max }$ 5.09; $\mathrm{SUV}_{\text {mean }} 2.43$; $\left.\mathrm{SUV}_{\text {peak }} 2.31\right)$ compared with patients with wild-type DNA (median $\mathrm{SUV}_{\max }$ 3.19; $\mathrm{SUV}_{\text {mean }}$ 2.06; $\left.\mathrm{SUV}_{\text {peak }} 2.40\right)$; however, this difference was not significant $(p=0.07)$ (Table 3, Fig. 6a).

Subgroup Analysis of Lobular and Invasive Ductal Carcinomas Revealed the Following Results In lobular carcinomas, mutational carriers had a lower median $\left[{ }^{18} \mathrm{~F}\right] \mathrm{FDG}$ uptake (median $\mathrm{SUV}_{\text {max }} 2.19 ; \mathrm{SUV}_{\text {mean }} 1.79 ; \mathrm{SUV}_{\text {peak }} 1.64$ ) than patients with wild-type DNA (median $\mathrm{SUV}_{\max } 2.36$; $\mathrm{SUV}_{\text {mean }} 1.52$; $\left.\mathrm{SUV}_{\text {peak }} 1.51\right)$; however, this difference was not significant $(p=0.86)$.

In invasive ductal carcinomas, $\left[{ }^{18} \mathrm{~F}\right] \mathrm{FDG}$ uptake was higher in PIK3CA mutational carriers $\left(\mathrm{SUV}_{\max }\right.$ 5.74, $\mathrm{SUV}_{\text {mean }}$ 2.46, $\mathrm{SUV}_{\text {peak }}$ 2.37) compared to wild-type tumors $\left(\mathrm{SUV}_{\max } 3.56, \mathrm{SUV}_{\text {mean }} 2.2, \mathrm{SUV}_{\text {peak }} 2.44\right)$ with a $p=0.5 .\left[{ }^{18} \mathrm{~F}\right]$ FDG uptake was elevated in all nuclear grades (Fig. 6b) for mutational carriers but was only statistically different from that of patients with wild-type DNA in grade 3 tumors $\left(\mathrm{SUV}_{\max } 8.55\right.$ vs. 5.07; $\mathrm{SUV}_{\text {mean }}$ 4.15 vs. 2.75; $\mathrm{SUV}_{\text {peak }} 6.71$ vs. 3.56) $(p=0.03)$ while remaining only visually apparent in grade $1(p=0.07)$ and grade 2 tumors $(p=0.15)$. Multivariate analysis using linear regression function revealed that $\left[{ }^{18} \mathrm{~F}\right] \mathrm{FDG}$ uptake is independently associated with PIK3CA mutational status $\left(\mathrm{SUV}_{\max }: \mathrm{B}=2.534\right.$, standard error 0.617 , $p=0.002 ; \mathrm{SUV}_{\text {mean }}: \mathrm{B}=0.812$; standard error $0.278, p=$ 0.009 ; $\mathrm{SUV}_{\text {peak }}: \mathrm{B}=1.168$, standard error $0.487, p=$ $0.023)$ and nuclear grade $\left(\mathrm{SUV}_{\max }: \mathrm{B}=1.225\right.$, standard error $0.63, p=0.046 ; \mathrm{SUV}_{\text {mean }}: \mathrm{B}=1.03$, standard error $0.251, p=0.001 ; \mathrm{SUV}_{\text {peak }}: \mathrm{B}=1.743$, standard error $0.381, p=0.001)$. Proliferation status showed likelihood of little effect on glycolytic activity $(\mathrm{B}=1.671$, standard error 0.894, $p=0.065)$. Largest tumor diameter $(p=$ $0.42)$, tumor volume $(p=0.38)$, and nodal status ( $p=$ $0.44)$ showed no influence on glycolytic activity. Adjusted $R^{2}$ was 0.381 .

To study the effects of PIK3CA mutational status on $\mathrm{SUV}_{\max }$ without the influence of nuclear grading, we used the binary logistic regression function to normalize this variable. We determined that PIK3CA mutational status exerted a specific influence on glycolytic metabolism (Nagelkerke's pseudo- $R^{2}$ 0.496; $p=0.02$ ). The Hosmer and Lemeshow test yielded $p=0.644$, corroborating the robustness of the model.

In summary, PIK3CA mutations were associated with increased glycolytic activity in ductal carcinomas. This effect was not found in lobular carcinomas. 

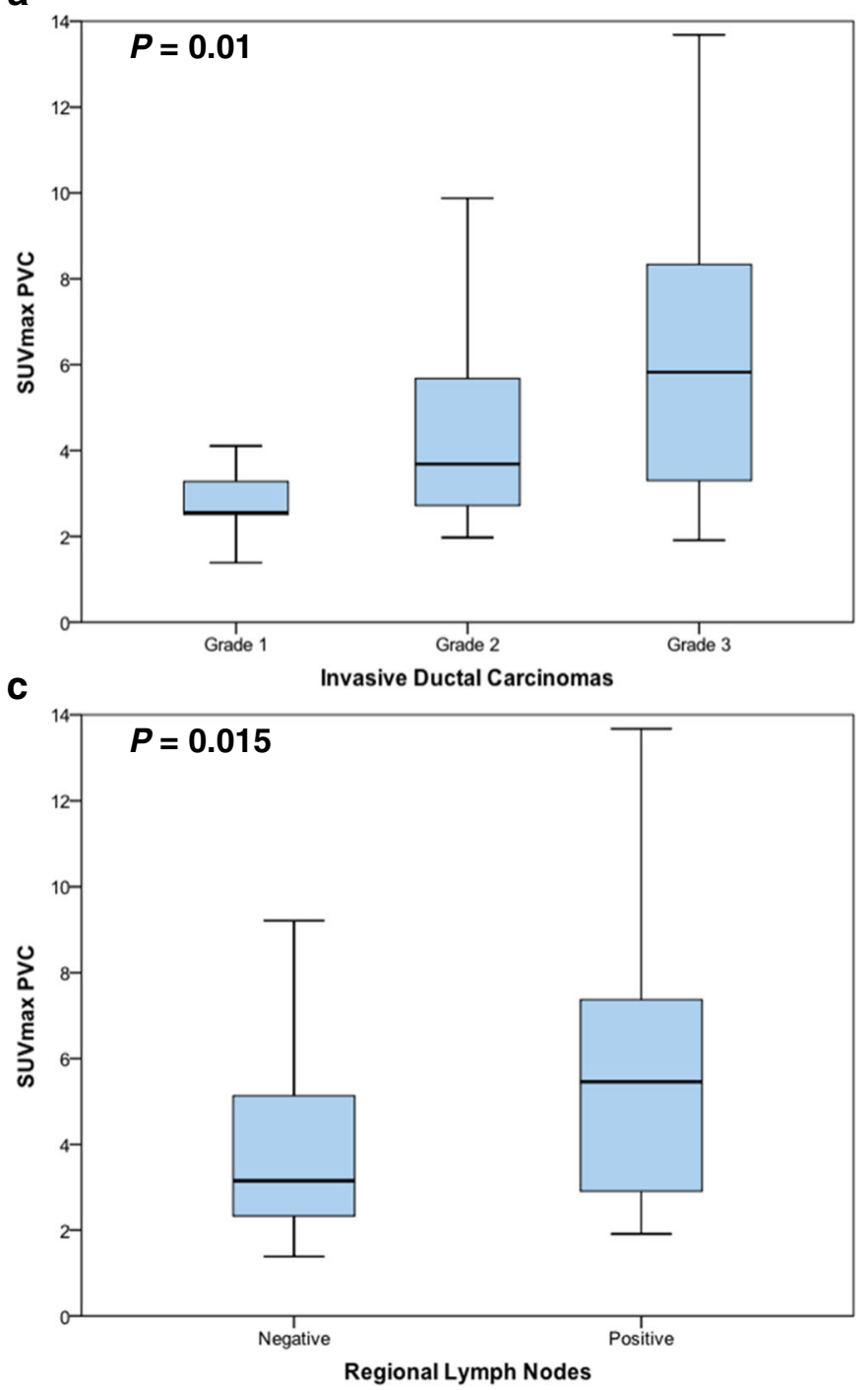

b

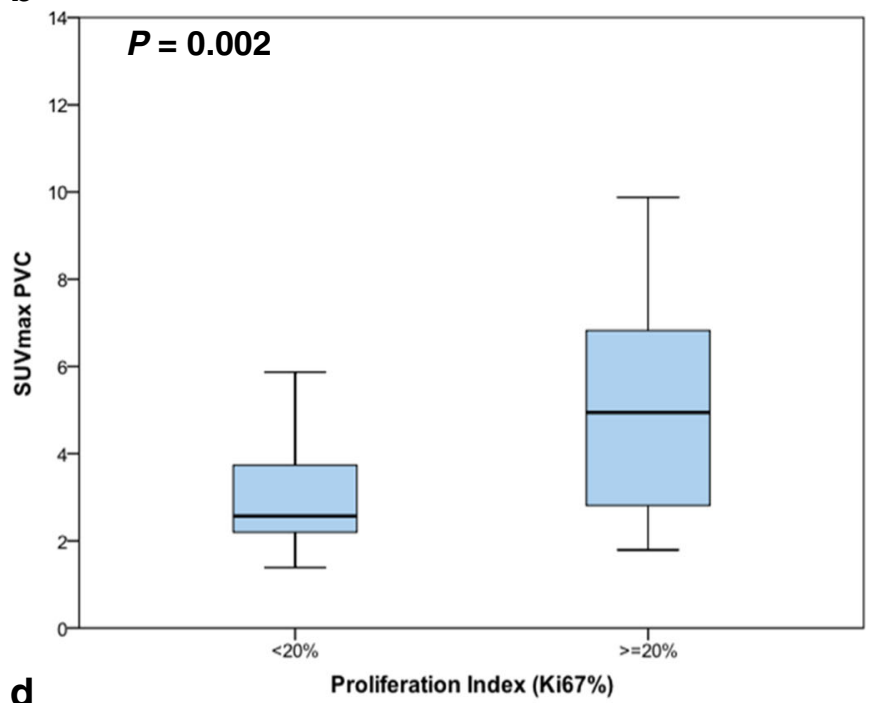

d

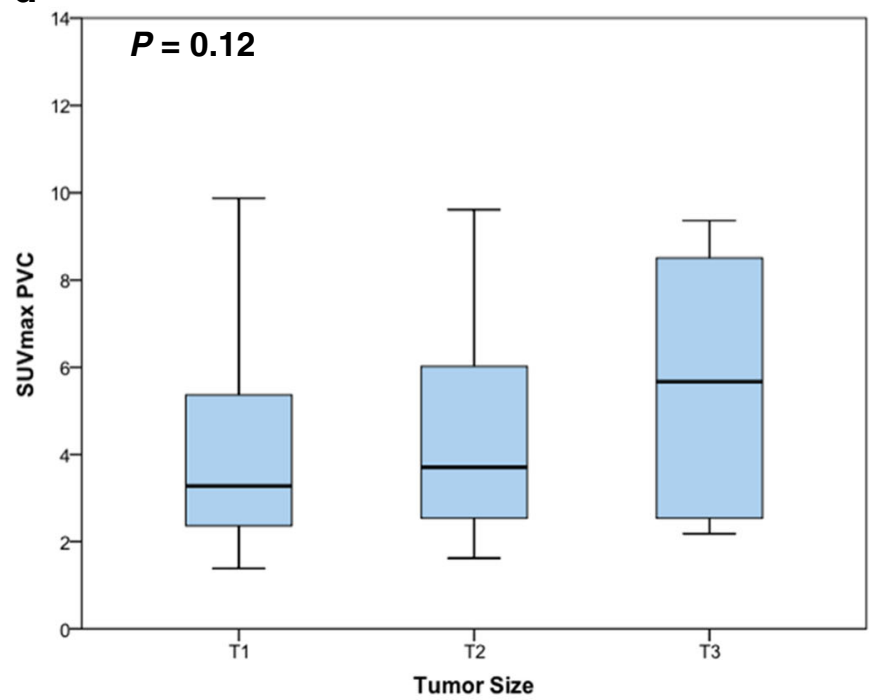

Fig. 5. Four boxplots illustrate median $S V_{\max } P V C$ levels with interquartile range of a nuclear grades (ductal carcinomas), $\mathbf{b}$ proliferation index, c axillary lymph nodes, and $\mathbf{d}$ tumor size. SUV $\max$ was positively associated with high nuclear grade (Kruskal-Wallis one-way ANOVA), with increased cellular proliferation and regional lymph node metastasis (Wilcoxon-MannWhitney $U$ ). Tumor size did not correlate with SUV $\max$ (linear regression model).

\section{Discussion}

In this study, we investigated the associations of PIK3CA mutational status, clinico-pathologic factors, and glycolytic activity as measured by $\left[{ }^{18} \mathrm{~F}\right] \mathrm{FDG}$ PET/CT in a cohort of ER+/HER2 - early breast cancer patients. PIK3CA mutational analysis and its association with downstream glycolytic activity were retrospectively assessed.

We show (i) a positive association of PIK3CA mutations with clinico-pathologic tumor features that demonstrate a low risk of recurrence, (ii) an increase in glycolytic activity in the presence of aggressive clinico-pathologic tumor features, and (iii) PIK3CA status and nuclear grade to be independently associated with glycolytic activity in invasive ductal carcinomas.

In our study, almost half of all tumors showed a PIK3CA mutation and the majority occurred in tumors with clinicopathologic features typically associated with a lowrecurrence risk. This data, both in terms of frequency and association, are in good agreement with several similar data sets [4, 40, 41]. Although there was no significant difference in RFS and DSS between patients with a PIK3CA mutant and wild-type tumors, wild-type tumors showed a trend of shorter RFS. This is concordant with survival analysis in groups of ER+ tumors with low- to intermediate-risk profiles 
Table 2. Invasive ductal and invasive lobular breast tumors. Nuclear tumor grade has significant impact on median (partial-volume corrected) $\mathrm{SUV}$ max, which is displayed in this table

\begin{tabular}{|c|c|c|c|c|}
\hline Histopathology & Number & Median $\mathrm{SUV}_{\max }$ (interquartile range) & $p$ value & \\
\hline Invasive ductal carcinoma grade 1 & 9 & $\begin{array}{l}2.56 \\
(2.25-3.69)\end{array}$ & 0.01 & 0.02 \\
\hline Invasive ductal carcinoma grade 2 & 19 & $\begin{array}{l}3.69 \\
(2.58-5.74)\end{array}$ & & \\
\hline Invasive ductal carcinoma grade 3 & 24 & $\begin{array}{l}5.82 \\
(3.25-8.42)\end{array}$ & & \\
\hline Invasive lobular carcinoma grade 2 & 11 & $\begin{array}{l}2.21 \\
(1.93-3.74)\end{array}$ & & \\
\hline
\end{tabular}

indicate that mutations in the p1 $10 \alpha$ catalytic subunit of the phosphatidylinositol-3-kinase in particular lower the risk of distant metastasis [42, 43].

Furthermore, the association of aggressive tumor features with $\left[{ }^{18} \mathrm{~F}\right] \mathrm{FDG}$ uptake is in line with basic tumor biology. The typical hallmarks of cancer, including invasion, metastasis, activation of angiogenesis, and sustained proliferative signaling cannot occur without the presence of increased energy metabolism, which includes glycolysis under both aerobic and anaerobic conditions [44]. However, in our study, tumor size was not associated with glycolytic metabolism, which was unexpected. Previous studies have reported the exact opposite extensively [45-47]. Key to this discrepancy seems to be the partial volume effect. Similar to our study, Antunovic et al. performed partial volume correction on their metric SUV data and similarly missed an association of size and metabolism [48]. We believe partial volume correction is a crucial feature which is not discussed broadly enough, but is essential for future studies and clinically relevant for therapy monitoring [49]. The distribution of tumor size may also account for its lack of influencing the model in a statistically meaningful way. The distribution of tumor sizes in our population was fairly even, thus making statistically relevant findings more unlikely.

To our knowledge, this was the first study to investigate the effect of PIK3CA mutations on glucose metabolism in an ER+/ HER 2- breast cancer collective. PIK3CA status was the strongest independent predictor of $\left[{ }^{18} \mathrm{~F}\right] \mathrm{FDG}$ uptake in invasive ductal carcinomas. However, mutated lobular cancers demonstrated no difference in $\left[{ }^{18} \mathrm{~F}\right] \mathrm{FDG}$ uptake which can be explained by its profoundly different molecular biology $[50,51]$.
These results demonstrate that glucose metabolism is at least partially affected by PIK3CA mutations. Recent data from the BIG 1-98 translational study group [9] have particular relevance to our data since both clinico-pathologic and demographic data were similar to those of our small sample; in that study, the association of PIK3CA mutations to low-risk tumor profiles was confirmed. In addition to our data, the coexistence of other oncogenic driver alterations in $76 \%$ of all PIK3CA mutations was also described. Interestingly, in these authors' dataset, 11q13 amplifications conferred a detrimental risk of distant metastasis in the presence of PIK3CA mutations. In the absence of 11q13 amplification (PIK3CA mutation alone), a positive prognostic effect was observed, leading to a statistically significant interaction term. The results of the current study further support the hypothesis that other downstream effectors and their alterations may influence glucose uptake and may be responsible for the somewhat counterintuitive findings of on one hand a positive association of PIK3CA mutations with clinico-pathologic tumor features that demonstrate a low risk of recurrence and on the other hand a positive association of $P I K 3 C A$ status and nuclear grade with glycolytic activity in invasive ductal carcinomas.

As mutations in PIK3CA, that encoding the insulinactivated PI3K, are among the most frequent events in human cancers, there has been great interest to use them as therapeutic targets. However, inhibition of PI3K in cancer patients yielded variable clinical responses indicating that that there might be inherent mechanism of resistance. In a most recent letter by Hopkins et al., the authors show in several tumor models that systemic glucose-insulin feedback

Table 3. Association between $P I K 3 C A$ mutations and $\mathrm{SUV}_{\max }$ in the whole study population

\begin{tabular}{|c|c|c|c|}
\hline PIK $3 C A$ & Number & Median $\mathrm{SUV}_{\max }$ (interquartile range) & $p$ value \\
\hline Wild-type & 37 & $\begin{array}{l}3.19 \\
(2.27-5.1)\end{array}$ & 0.07 \\
\hline Mutation & 30 & $\begin{array}{l}5.09 \\
(2.68-7.16)\end{array}$ & \\
\hline Exon 20 mutation & 15 & $\begin{array}{l}5.62 \\
(2.87-6.82)\end{array}$ & 0.42 \\
\hline Exon 9 mutation & 10 & $\begin{array}{l}5.09 \\
(2.76-6.9)\end{array}$ & \\
\hline Exon 7 mutation & 1 & $\begin{array}{l}1.62 \\
\text { (NA) }\end{array}$ & \\
\hline Exon 4 mutation & 4 & $\begin{array}{l}5.35 \\
(2.52-8.42)\end{array}$ & \\
\hline
\end{tabular}


a

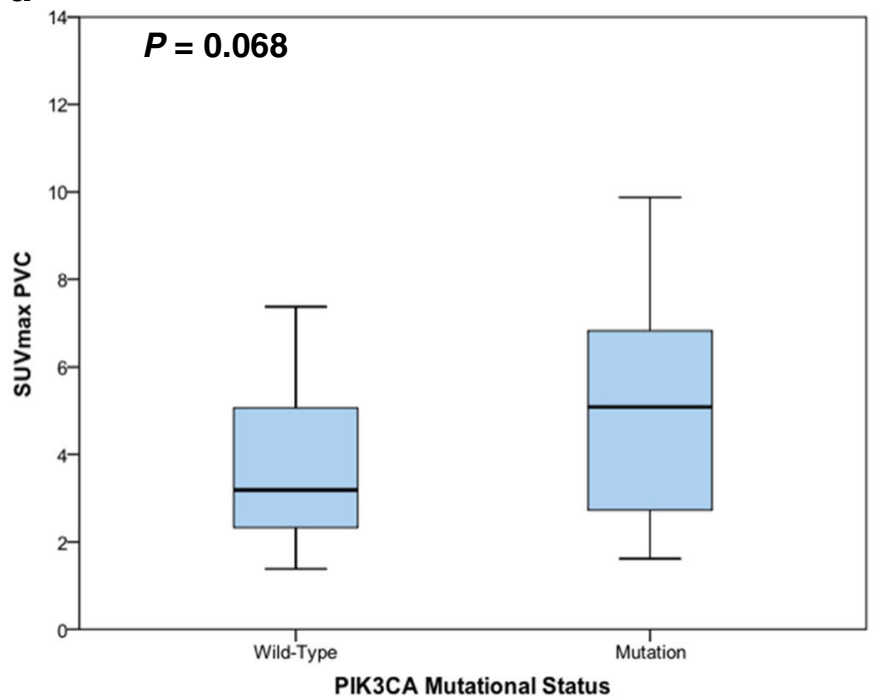

b

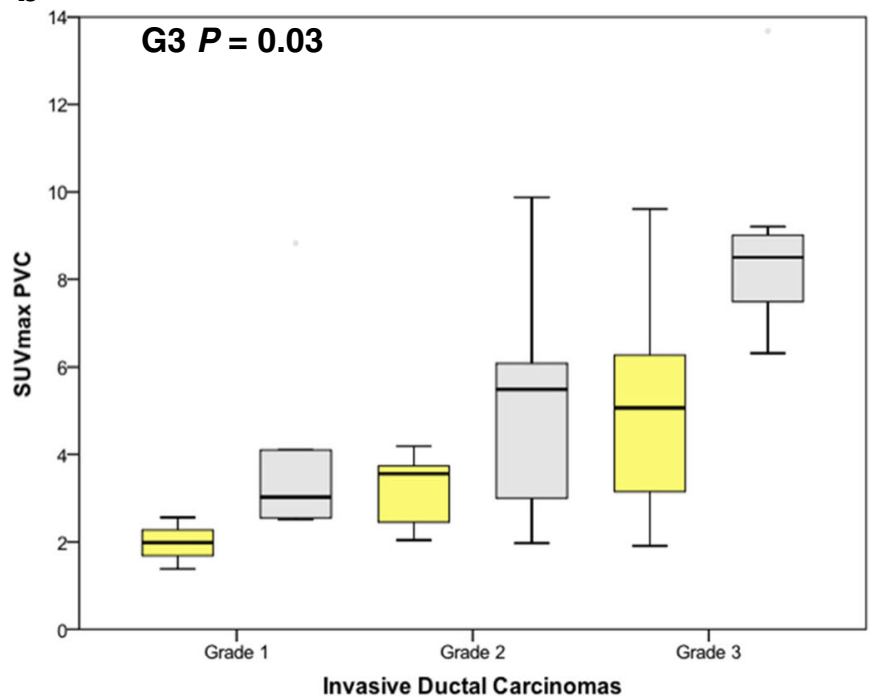

Fig. 6. a Glycolytic metabolism was enhanced in PIK3CA mutated breast tumors (Wilcoxon-Mann-Whitney U). In invasive ductal carcinomas, only PIK3CA mutational status and nuclear grading independently influenced glycolytic metabolism. $\mathbf{b}$ The influence of PIK3CA mutations is illustrated by discriminating nuclear grades of ductal carcinomas. It is easily recognized that glycolytic activity is raised in mutated tumors compared with wild-type tumors independent of nuclear grade (mutations in gray; wild-type in yellow).

caused by targeted inhibition of the PI3K-mTOR signaling axis is sufficient to activate PI3K signaling, even in the presence of PI3K inhibitors [5]. They demonstrated that suppression of insulin feedback by dietary or pharmaceutical approaches enhances the efficacy of PI3K inhibitors. In this study, they also performed $\left[{ }^{18} \mathrm{~F}\right] \mathrm{FDG}$ PET imaging on mice bearing orthotopic Kras-Tp53-Pdx-Cre (KPC) tumor allografts to evaluate whether PI3K inhibitor-induced spikes in glucose and insulin were affecting tumors to an extent that can be captured with non-invasive $\left[{ }^{18} \mathrm{~F}\right] \mathrm{FDG}$ PET imaging. They found that spikes in insulin in the acute setting after PI3K inhibition cause an increase in $\left[{ }^{18} \mathrm{~F}\right] \mathrm{FDG}$ uptake in tumors.

Although the current study is limited by a small sample size, this data analysis led to the emergence of an intriguing new hypothesis: molecular imaging seems to be able to describe functional tumor features that reflect highly complex genomic alterations independently of classic clinico-pathologic features. The recent results by Hopkins et al. as well as our own support the idea that $\left[{ }^{18} \mathrm{~F}\right] \mathrm{FDG}$ $\mathrm{PET} / \mathrm{CT}$ may potentially serve as candidate biomarker for monitoring therapeutic response and resistance mechanisms in emerging therapies that target the $\mathrm{Pi} 3 \mathrm{~K} / \mathrm{AKT} / \mathrm{mTOR}$ pathway. However, these initial results need to be validated in prospective larger scale studies. Although PIK3CA can show alterations in other types of breast cancer such as TNBC or HER2+, these alterations are much rarer and drug development targeting this pathway is very much focused on the ER+ HER2- subset. Therefore, the intended focus of the paper was to analyze the PI3K/AKT/mTOR pathway in ER+/HER2 - early invasive breast cancer as a particular biologic subset of breast cancer.

\section{Conclusion}

In ER+/HER2 - early invasive breast cancer of the ductal subtype glucose metabolism is independently associated with mutations in PIK3CA. Although $\left[{ }^{18} \mathrm{~F}\right] \mathrm{FDG}$ PET/CT does not seem ideal for identifying PIK3CA mutations, initial data suggest that $\left[{ }^{18} \mathrm{~F}\right] \mathrm{FDG}$ uptake reflects complex genomic alterations and may have the potential to be used as candidate biomarker for monitoring therapeutic response and resistance mechanisms in emerging therapies that target the $\mathrm{PI} 3 \mathrm{~K} / \mathrm{AKT} / \mathrm{mTOR}$ pathway.

Acknowledgements. Open access funding provided by Medical University of Vienna.

Funding. Funding was provided by the Austrian Nationalbank "Jubiläumsfond" Project Nr. 16219, Nr. 15082, the 2020 - Research and Innovation Framework Programme PHC-11-2015 Nr. 667211-2, and seed grants from Siemens Austria, Novomed, Medicor Austria, and Guerbet, France. Katja Pinker was also supported by the National Institutes of Health/National Cancer Institute Cancer Center Support Grant P30 CA008748.

Availability of Data and Material. The datasets used and/or analyzed during the current study are available from the corresponding author upon reasonable request.

\section{Compliance with Ethical Standards}

\section{Ethical Approval}

All procedures performed in studies involving human participants were in accordance with the ethical standards of the institutional and/or national research committee and with the 1964 Helsinki declaration and its later amendments or comparable ethical standards. For this type of study, formal consent is not required. This article does not contain any studies with animals performed by any of the authors. 


\section{Informed Consent}

Informed consent was obtained from all individual participants included in the study.

\section{Conflict of Interests}

The authors declare that they have no conflict of interest.

Open Access This article is distributed under the terms of the Creative Commons Attribution 4.0 International License (http:// creativecommons.org/licenses/by/4.0/), which permits unrestricted use, distribution, and reproduction in any medium, provided you give appropriate credit to the original author(s) and the source, provide a link to the Creative Commons license, and indicate if changes were made.

Publisher's note Springer Nature remains neutral with regard to jurisdictional claims in published maps and institutional affiliations.

\section{References}

1. Engelman JA (2009) Targeting PI3K signalling in cancer: opportunities, challenges and limitations. Nat Rev Cancer 9:550-562

2. Ciruelos Gil EM (2014) Targeting the PI3K/AKT/mTOR pathway in estrogen receptor-positive breast cancer. Cancer Treat Rev 40:862871

3. Miller TW, Rexer BN, Garrett JT, Arteaga CL (2011) Mutations in the phosphatidylinositol 3-kinase pathway: role in tumor progression and therapeutic implications in breast cancer. Breast Cancer Res 13:224

4. Mukohara T (2015) PI3K mutations in breast cancer: prognostic and therapeutic implications. Breast Cancer (Dove Med Press) 7:111-123

5. Hopkins BD, Pauli C, Du X, et al (2018) Suppression of insulin feedback enhances the efficacy of PI3K inhibitors. Nature

6. Kalinsky K, Heguy A, Bhanot UK, Patil S, Moynahan ME (2011) PIK3CA mutations rarely demonstrate genotypic intratumoral heterogeneity and are selected for in breast cancer progression. Breast Cancer Res Treat 129:635-643

7. Barone I, Cui Y, Herynk MH, Corona-Rodriguez A, Giordano C, Selever J, Beyer A, Ando S, Fuqua SAW (2009) Expression of the $\mathrm{K} 303 \mathrm{R}$ estrogen receptor-alpha breast cancer mutation induces resistance to an aromatase inhibitor via addiction to the PI3K/Akt kinase pathway. Cancer Res 69:4724-4732

8. Cavazzoni A, Bonelli MA, Fumarola C, la Monica S, Airoud K, Bertoni R, Alfieri RR, Galetti M, Tramonti S, Galvani E, Harris AL, Martin LA, Andreis D, Bottini A, Generali D, Petronini PG (2012) Overcoming acquired resistance to letrozole by targeting the PI3K/ AKT/mTOR pathway in breast cancer cell clones. Cancer Lett 323:77-87

9. Loi SAR, Lee C, Luen S, Savas PColleoni M (2016) Clinical implications of somatic mutations in post-menopausal early-stage estrogen receptor (ER)-positive, HER2- breast cancer: results from the BIG 1-98 study. In San Antonio Breast Cancer Symposium. San Antonio, United States

10. Ortega AD, Sanchez-Arago M, Giner-Sanchez D et al (2009) Glucose avidity of carcinomas. Cancer Lett 276:125-135

11. Cairns RA, Harris IS, Mak TW (2011) Regulation of cancer cell metabolism. Nat Rev Cancer 11:85-95

12. Elstrom RL, Bauer DE, Buzzai M, Karnauskas R, Harris MH, Plas DR, Zhuang H, Cinalli RM, Alavi A, Rudin CM, Thompson CB (2004) Akt stimulates aerobic glycolysis in cancer cells. Cancer Res 64:3892-3899

13. Nguyen Q-D, Perumal M, Waldman TA, Aboagye EO (2011) Glucose metabolism measured by [18F]fluorodeoxyglucose positron emission tomography is independent of PTEN/AKT status in human Colon carcinoma cells. Trans Oncol 4:241-248

14. Sun Q, Chen X, Ma J, Peng H, Wang F, Zha X, Wang Y, Jing Y, Yang H, Chen R, Chang L, Zhang Y, Goto J, Onda H, Chen T, Wang MR, Lu Y, You H, Kwiatkowski D, Zhang H (2011) Mammalian target of rapamycin up-regulation of pyruvate kinase isoenzyme type M2 is critical for aerobic glycolysis and tumor growth. Proc Natl Acad Sci U S A 108:4129-4134
15. Avril N, Adler LP (2007) F-18 fluorodeoxyglucose-positron emission tomography imaging for primary breast cancer and loco-regional staging. Radiol Clin N Am 45:645-657 vi

16. Quon A, Gambhir SS (2005) FDG-PET and beyond: molecular breast cancer imaging. J Clin Oncol 23:1664-1673

17. Adli M, Kuzhan A, Alkis H, Andic F, Yilmaz M (2013) FDG PET uptake as a predictor of pain response in palliative radiation therapy in patients with bone metastasis. Radiology 269:850-856

18. Avril S, Muzic RF Jr, Plecha D et al (2016) ${ }^{18} \mathrm{~F}-\mathrm{FDG}$ PET/CT for monitoring of treatment response in breast Cancer. J Nucl Med 57(Suppl 1):34S-39S

19. Dose Schwarz J, Bader M, Jenicke L et al (2005) Early prediction of response to chemotherapy in metastatic breast cancer using sequential ${ }^{18}$ F-FDG PET. J Nucl Med 46:1144-1150

20. Humbert O, Cochet A, Coudert B, Berriolo-Riedinger A, Kanoun S, Brunotte F, Fumoleau P (2015) Role of positron emission tomography for the monitoring of response to therapy in breast cancer. Oncologist 20:94-104

21. Humbert O, Riedinger JM, Vrigneaud JM, Kanoun S, Dygai-Cochet I, Berriolo-Riedinger A, Toubeau M, Depardon E, Lassere M, Tisserand S, Fumoleau P, Brunotte F, Cochet A (2016) ${ }^{18}$ F-FDG PET-derived tumor blood flow changes after 1 cycle of neoadjuvant chemotherapy predicts outcome in triple-negative breast cancer. J Nucl Med $57: 1707-1712$

22. Koolen BB, Vogel WV, Vrancken et al $(2012,2012)$ Molecular imaging in breast Cancer: from whole-body PET/CT to dedicated breast PET. J Oncol:438647

23. Lei L, Wang X, Chen Z (2016) PET/CT imaging for monitoring recurrence and evaluating response to treatment in breast cancer. Adv Clin Exp Med 25:377-382

24. Liu Q, Wang C, Li P et al (2016) The role of ${ }^{18}$ F-FDG PET/CT and MRI in assessing pathological complete response to neoadjuvant chemotherapy in patients with breast cancer: a systematic review and meta-analysis. Biomed Res Int 2016:3746232

25. Magometschnigg HF, Baltzer PA, Fueger B, Helbich TH, Karanikas G, Dubsky P, Rudas M, Weber M, Pinker K (2015) Diagnostic accuracy of ${ }^{18} \mathrm{~F}-\mathrm{FDG}$ PET/CT compared with that of contrastenhanced MRI of the breast at 3 T. Eur J Nucl Med Mol Imaging 42:1656-1665

26. Mortazavi-Jehanno N, Giraudet AL, Champion L, Lerebours F, le Stanc E, Edeline V, Madar O, Bellet D, Pecking AP, Alberini JL (2012) Assessment of response to endocrine therapy using FDG PET/ CT in metastatic breast cancer: a pilot study. Eur J Nucl Med Mol Imaging 39:450-460

27. Moy L, Noz ME, Maguire GQ Jr, Ponzo F, Deans AE, MurphyWalcott AD, Kramer EL (2007) Prone mammoPET acquisition improves the ability to fuse MRI and PET breast scans. Clin Nucl Med 32:194-198

28. Pinker K, Bogner W, Baltzer P, Karanikas G, Magometschnigg H, Brader P, Gruber S, Bickel H, Dubsky P, Bago-Horvath Z, Bartsch R, Weber M, Trattnig S, Helbich TH (2014) Improved differentiation of benign and malignant breast tumors with multiparametric 18 fluorodeoxyglucose positron emission tomography magnetic resonance imaging: a feasibility study. Clin Cancer Res 20:3540-3549

29. Pinker K, Riedl CC, Ong L, Jochelson M, Ulaner GA, McArthur H, Dickler M, Gonen M, Weber WA (2016) The impact that number of analyzed metastatic breast Cancer lesions has on response assessment by ${ }^{18}$ F-FDG PET/CT using PERCIST. J Nucl Med 57:1102-1104

30. Weber WA (2009) Assessing tumor response to therapy. J Nucl Med 50(Suppl 1):1S-10S

31. Yutani K, Tatsumi M, Uehara T, Nishimura T (1999) Effect of patients' being prone during FDG PET for the diagnosis of breast cancer. AJR Am J Roentgenol 173:1337-1339

32. Bouin AS, Wierer M (2014) Quality standards of the European Pharmacopoeia. J Ethnopharmacol 158(Pt B):454-457

33. Hamacher K, Coenen HH (2002) Efficient routine production of the 18F-labelled amino acid O-2-18F fluoroethyl-L-tyrosine. Appl Radiat Isot 57:853-856

34. Knausl B, Hirtl A, Dobrozemsky G et al (2012) PET based volume segmentation with emphasis on the iterative TrueX algorithm. Z Med Phys 22:29-39

35. Knausl B, Rausch IF, Bergmann $H$ et al (2013) Influence of PET reconstruction parameters on the TrueX algorithm. A combined phantom and patient study. Nuklearmedizin 52:28-35 
36. Rapisarda E, Bettinardi V, Thielemans K, Gilardi MC (2010) Imagebased point spread function implementation in a fully 3D OSEM reconstruction algorithm for PET. Phys Med Biol 55:4131-4151

37. Graham MM, Peterson LM, Hayward RM (2000) Comparison of simplified quantitative analyses of FDG uptake. Nucl Med Biol 27:647-655

38. Nosho K, Kawasaki T, Ohnishi M et al (2008) PIK3CA mutation in colorectal cancer: relationship with genetic and epigenetic alterations. Neoplasia 10:534-541

39. Senkus E, Kyriakides S, Ohno S, Penault-Llorca F, Poortmans P, Rutgers E, Zackrisson S, Cardoso F (2015) Primary breast cancer: ESMO clinical practice guidelines for diagnosis, treatment and followup. Ann Oncol 26(Suppl 5):v8-v30

40. Liu YR, Jiang YZ, Zuo WJ et al (2014) PIK3CA mutations define favorable prognostic biomarkers in operable breast cancer: a systematic review and meta-analysis. Onco Targets Ther 7:543-552

41. Pang B, Cheng S, Sun SP et al (2014) Prognostic role of PIK3CA mutations and their association with hormone receptor expression in breast cancer: a meta-analysis. Sci Rep 4:6255

42. Dumont AG, Dumont SN, Trent JC (2012) The favorable impact of PIK3CA mutations on survival: an analysis of 2587 patients with breast cancer. Chin J Cancer 31:327-334

43. Sabine VS, Crozier C, Brookes CL, Drake C, Piper T, van de Velde CJH, Hasenburg A, Kieback DG, Markopoulos C, Dirix L, Seynaeve C, Rea DW, Bartlett JMS (2014) Mutational analysis of PI3K/AKT signaling pathway in tamoxifen exemestane adjuvant multinational pathology study. J Clin Oncol 32:2951-2958

44. Hanahan D, Weinberg RA (2011) Hallmarks of cancer: the next generation. Cell 144:646-674

45. De Cicco C, Gilardi L, Botteri E et al (2013) Is $\left[{ }^{18} \mathrm{~F}\right]$ fluorodeoxyglucose uptake by the primary tumor a prognostic factor in breast cancer? Breast 22:39-43

46. Kitajima K, Yamano T, Fukushima K et al (2016) Correlation of the SUVmax of FDG-PET and ADC values of diffusion-weighted MR imaging with pathologic prognostic factors in breast carcinoma. Eur J Radiol 85:943-949

47. Lee J, Lee EJ, Moon SH, Kim S, Hyun SH, Cho YS, Choi JY, Kim BT, Lee KH (2017) Strong association of epidermal growth factor receptor status with breast cancer FDG uptake. Eur J Nucl Med Mol Imaging 44:1438-1447
48. Antunovic L, Gallivanone F, Sollini $\mathrm{M}$ et al (2017) $\left[{ }^{18} \mathrm{~F}\right] \mathrm{FDG}$ PET/CT features for the molecular characterization of primary breast tumors. Eur J Nucl Med Mol Imaging 44:1945-1954

49. Stefano A, Gallivanone F, Messa C et al (2014) Metabolic impact of partial volume correction of $\left[{ }^{18} \mathrm{~F}\right] \mathrm{FDG}$ PET-CT oncological studies on the assessment of tumor response to treatment. Q J Nucl Med Mol Imaging 58:413-423

50. Avril N, Menzel M, Dose J et al (2001) Glucose metabolism of breast cancer assessed by $18 \mathrm{~F}-\mathrm{FDG}$ PET: histologic and immunohistochemical tissue analysis. J Nucl Med 42:9-16

51. Ciriello G, Gatza ML, Beck AH, Wilkerson MD, Rhie SK, Pastore A, Zhang H, McLellan M, Yau C, Kandoth C, Bowlby R, Shen H, Hayat S, Fieldhouse R, Lester SC, Tse GMK, Factor RE, Collins LC, Allison KH, Chen YY, Jensen K, Johnson NB, Oesterreich S, Mills GB, Cherniack AD, Robertson G, Benz C, Sander C, Laird PW, Hoadley KA, King TA, Perou CM, Akbani R, Auman JT, Balasundaram M, Balu S, Barr T, Beck A, Benz C, Benz S, Berrios M, Beroukhim R, Bodenheimer T, Boice L, Bootwalla MS, Bowen J, Bowlby R, Brooks D, Cherniack AD, Chin L, Cho J, Chudamani S, Ciriello G, Davidsen T, Demchok JA, Dennison JB, Ding L, Felau I, Ferguson ML, Frazer S, Gabriel SB, Gao JJ, Gastier-Foster JM, Gatza ML, Gehlenborg N, Gerken M, Getz G, Gibson WJ, Hayes DN, Heiman DI, Hoadley KA, Holbrook A, Holt RA, Hoyle AP, Hu H, Huang M, Hutter CM, Hwang ES, Jefferys SR, Jones SJM, Ju Z, Kim J, Lai PH, Laird PW, Lawrence MS, Leraas KM, Lichtenberg TM, Lin P, Ling S, Liu J, Liu W, Lolla L, Lu Y, Ma Y, Maglinte DT, Mardis E, Marks J, Marra MA, McAllister C, McLellan M, Meng S, Meyerson M, Mills GB, Moore RA, Mose LE, Mungall AJ, Murray BA, Naresh R, Noble MS, Oesterreich S, Olopade O, Parker JS, Perou CM, Pihl T, Saksena G, Schumacher SE, Shaw KRM, Ramirez NC, Rathmell WK, Rhie SK, Roach J, Robertson AG, Saksena G, Sander C, Schein JE, Schultz N, Shen H, Sheth M, Shi Y, Shih J, Shelley CS, Shriver C, Simons JV, Sofia HJ, Soloway MG, Sougnez C, Sun C, Tarnuzzer R, Tiezzi DG, van den Berg DJ, Voet D, Wan Y, Wang Z, Weinstein JN, Weisenberger DJ, Wilkerson MD, Wilson R, Wise L, Wiznerowicz M, Wu J, Wu Y, Yang L, Yau C, Zack TI, Zenklusen JC, Zhang H, Zhang J, Zmuda E (2015) Comprehensive molecular portraits of invasive lobular breast cancer. Cell 163:506-519 